\title{
Tema central: Soberanía y Territorio
}

\section{Presentación}

La relación entre geografías y espacios políticos en Iberoamérica está siendo revisada. Frente a los enfoques deterministas y esencialistas de la nación, cuyo objetivo era contribuir a la afirmación de los estados existentes como resultados "naturales" o "prefigurados", se han ido abriendo caminos nuevos en la historiografía que dan cuenta de las complejas relaciones entre soberanía y territorios y de sus resignificaciones en los siglos XVIII y XIX. De esa forma, por ejemplo, la indefinición relativa de los límites jurisdiccionales y los conflictos suscitados en todas las escalas territoriales en el espacio americano ya no se ven como anomalías o desvíos al "destino nacional", sino que se estudian a la luz de los rasgos de la cultura constitucional del mundo ibérico y su conceptualización acerca de la soberanía y los territorios.

Los artículos reunidos en este apartado constituyen aportes al estudio de las dinámicas espaciales en los dominios españoles y lusitanos en América, estudiando las transformaciones ocurridas a partir de la crisis de las monarquías ibéricas, las revoluciones de independencia y la formación de nuevos estados hasta la segunda mitad del siglo XIX. Indagan sobre los procesos de construcción territorial en la costa pacífica de los actuales estados de Ecuador y Colombia, el Brasil y la región del Río de la Plata, explorando la semántica de los conceptos que dan cuenta del ordenamiento del espacio. Permiten pensar y significar las complejas relaciones entre poderes políticos y jurisdiccionales en distintas escalas territoriales, la definición de fronteras y límites cuya cartografía -con la aplicación conflictiva del uti possidetis- surgió a mediados del siglo XVIII, así como la "lucha de soberanías", en la feliz expresión de Antonio Annino.

El trabajo de Lucía Rodríguez recoge un apartado de su tesis de maestría recientemente defendida y los de Federica Morelli, Helen Osório y Andréa Slemian son las versiones finales de ponencias presentadas en seminarios internacionales realizados en Montevideo, a saber: República, soberanía y 
territorios. A doscientos años de las Instrucciones del año XIII, 17-18 de setiembre de 2013 y A doscientos años del Reglamento de Tierras, 14-15 de setiembre de 2015. Este dossier se inscribe en las actividades del grupo "Territorio y Soberanía" del Proyecto y Red de Investigación en Historia Conceptual Comparada del mundo iberoamericano, más conocido por Iberconceptos III, que dirige Javier Fernández Sebastián, de la Universidad del País Vasco.

El artículo de Federica Morelli estudia el proceso de incorporación de una zona de frontera territorial y étnica en la costa del Pacífico -Esmeraldas- a una unidad política mayor: el imperio español y luego la República del Ecuador. A propósito de este caso, Morelli replantea las nociones de soberanía y territorio en el mundo español desde el siglo XVI, resaltando que la naturaleza jurisdiccional de los vínculos habilitaba la construcción de una soberanía espacialmente elástica. Es particularmente interesante el análisis de cómo en distintas coyunturas políticas, una sociedad mestiza afro-indígena, surgida como un palenque, desarrolló estrategias para resistir la conquista militar, negoció el mantenimiento de ciertos niveles de autonomía como cuerpo político y luchó por la libertad de los esclavizados.

El artículo de Lucía Rodríguez se inscribe en las relaciones entre los saberes territoriales y la construcción de poder institucional en el imperio español. Analiza un informe anónimo producido a fines del siglo XVIII sobre los "campos de Buenos Aires y Montevideo". A diferencia de la historiografía tradicional, que "leyó" el texto bajo el lente de la futura Provincia/Estado Oriental, Rodríguez se detiene particularmente en la demarcación espacial propuesta por el anónimo autor -quien lleva el límite oeste al río Paraná y el este al río Grande de San Pedro- y en sus planteos sobre los conflictos fronterizos entre las monarquías ibéricas. El artículo indaga también acerca del concepto de patria que se desprende del escrito, proponiendo que si bien el informe participó del proceso de configuración de identidades regionales americanas, en sintonía con los discursos sobre prosperidad económica y el fomento de artes útiles de las Sociedades Económicas de Amigos del País, las expediciones científicas, etc., debe ser leído en clave de "patriotismo hispánico" por entender que sus expresiones "adquirían sentido solo en clave imperial". 
El artículo de Helen Osório analiza los conceptos que dan cuenta del ordenamiento territorial de los dominios imperiales lusitanos, mostrando las diferencias, adaptaciones y reapropiaciones operadas en Brasil. En un estudio específico sobre la zona meridional, organizada hacia 1763 en capitanía de Río Grande de San Pedro, la autora constata el papel de las parroquias como referentes espaciales y administrativos con competencias que excedían las de una jurisdicción eclesiástica. Hasta avanzado el siglo XIX, las parroquias continuaron siendo los referentes para la organización de las milicias, los registros de tierras y los actos electorales, entre otras funciones. Osório estudia también las relaciones entre la extensión de la malla administrativa y el proceso de apropiación de tierras, comprobando el papel de los oficiales de milicias en los repartos, proceso que se acrecienta en el contexto de las expediciones armadas hacia la Banda/Provincia Oriental en el contexto de la Revolución del Río de la Plata.

El artículo de Andréa Slemian analiza las distinciones entre los territorios de la monarquía portuguesa, las disputas generadas en América en torno a la soberanía de los mismos y el surgimiento de nuevas identidades políticas. La autora dedica especial atención a la confrontación entre diversas concepciones de soberanía y estudia estos procesos en tres momentos: las propuestas del reformismo ilustrado lusitano de la segunda mitad del siglo XVIII, la presencia de la corte portuguesa en América y el establecimiento del Imperio de Brasil. En su análisis, Slemian tiende puentes con la experiencia hispanoamericana, presentando las tensiones entre la unidad de la nación y sus "partes" en la América portuguesa, así como la constitución de los lazos de cohesión que sustentaron el surgimiento del imperio brasileño, en un contexto pautado por una concepción de monarquía constitucional más moderada.

La lectura conjunta de los trabajos permite apreciar cómo, en espacios geográficos tan distantes como Esmeraldas, Brasil o el Río de la Plata, se verificaba la existencia de territorios de contornos borrosos, con fueros o privilegios que implicaban el solapamiento de espacios de poder, unidos fundamentalmente por su vínculo con el rey, quien ejercía su soberanía sobre grupos humanos y pueblos, y no necesariamente sobre la tierra.

Las reformas ilustradas impulsadas desde Madrid y Lisboa durante la segunda mitad del siglo XVIII buscaron la integración de los territorios a través 
del fortalecimiento de una soberanía monárquica. En ese proceso, como estudian los trabajos de Rodríguez y Slemian, se acrecentó el interés por el conocimiento geográfico de los dominios americanos, lo que contribuyó a conformar identidades territoriales en el marco de las monarquías.

La persistencia de la capacidad negociadora en defensa de fueros o del manejo de recursos naturales en espacios de frontera se aprecia particularmente en los artículos de Morelli y Osório. Ya fuera por las dificultades de acceso al lugar, las demandas de hombres en armas en una zona de conflictos de límites o la necesidad de promover la producción, entre otras razones, las autoridades locales estuvieron mejor posicionadas para gestionar la persistencia o acrecentamiento de ciertos beneficios institucionales o prerrogativas, aún después de las independencias.

Entre las líneas transversales a los cuatro artículos pueden mencionarse el impacto de las reformas ilustradas sobre las instituciones de base territorial de estas monarquías; los cambios y disputas en torno a la soberanía y sus conflictivas proyecciones espaciales después de las independencias; así como las transformaciones de los conceptos referidos al ordenamiento territorial y las relaciones entre las diversas unidades políticas y sus representantes a nivel internacional o, al interior de las mismas, entre los gobiernos centrales, las circunscripciones de tipo provincial y los espacios locales. Líneas que constituyen, además, ejes de trabajo del grupo "Territorio y soberanía” de Iberconceptos.

La vigencia de estos temas surge en ámbitos tan diversos como la discusión actual en torno a los derechos territoriales de las comunidades de origen amerindio o afrodescendiente, las demandas por una mayor descentralización gubernamental (municipios o alcaldías), las controversias limítrofes o los procesos de integración regional en América Latina. También, de la necesaria reflexión colectiva en el marco de las conmemoraciones bicentenarias. 